\title{
Replanning public transport services in the case of budget reductions
}

\author{
L. D’Acierno ${ }^{1}$, M. Gallo ${ }^{2}$, L. Biggiero ${ }^{1} \&$ B. Montella ${ }^{1}$ \\ ${ }^{1}$ Department of Civil, Architectural and Environmental Engineering, \\ 'Federico II' University of Naples, Italy \\ ${ }^{2}$ Department of Engineering, University of Sannio, Italy
}

\begin{abstract}
The planning of an efficient and effective public transport system is a key element in managing modern mobility both in densely populated urban areas and in peripheral and/or rural areas where the population densities are considerably lower. Indeed, the presence of public transport designed to meet travel demand could allow a reduction in negative externalities produced by private cars without excessively penalising user travel times or accessibility to different zones. However, the recent financial crisis has forced many public administrations to reduce resources allocated to public services and replan related services in order to mitigate negative effects on users. In this context, we propose two methods for replanning public transport services in the case of budget reductions. The first approach, indicated as CLP (Change the Least Possible), can be adopted when the initial services are actually able to satisfy user needs and in some time slots are probably surplus to requirements. The second approach, CFR (Change the FRamework), instead, should be used when the initial services are already inadequate or barely sufficient to serve users in the study area. Indeed, in the latter case, it is very difficult to eliminate some runs without producing a significant reduction in levels of service. Finally, the proposed methodology has been applied by our research group when replanning bus services in the provinces of Naples and Avellino, in southern Italy, where we implemented respectively the CLP and CFR approaches by solving some problems related to interference with pre-existing planning tools.

Keywords: public transport services, planning methods, mass-transit network design, real network analysis.
\end{abstract}




\section{Introduction}

The design of a transport system is an important element in the economic development of a country and/or a region. Since ancient times the first populations and their economic systems were developed in close proximity to major sea and river connections. Examples of such peoples are the Assyrians, the Babylonians, the Egyptians, the Phoenicians and the Greeks. Likewise, one of the main elements that led to the growth of Ancient Rome was the creation of the great consular roads which allowed swift connections between different parts of Rome's extensive possessions. The same consular roads, however, were used by Barbarians whose invasions contributed to the fall of the Roman Empire. Even the discovery of America and Oceania were dictated by the need to identify efficient transport routes between the East and the West of our planet.

A major issue in the current era is the development of sustainable transport systems which can use the 'limited' resources at our disposal both efficiently and effectively. In this context, the planning of an efficient and effective public transport system is a key element in managing modern mobility both in densely populated urban areas and in peripheral and/or rural areas where the population densities are considerably lower. Indeed, the presence of public transport designed to meet travel demand could allow a reduction in negative externalities (such as congestion, accidents, noise and air pollution) produced by private cars without excessively penalising user travel times or accessibility to different zones (as shown by [1]). The current trend in developing methods for reducing the use of private cars is highlighted by [2-5].

In the literature, the Mass Transit Network Design Problem (MTNDP) has been extensively studied. Detailed analysis of the general problem was provided by [6]. The MTNDP is an extremely complex problem due to its non-convexity [7-9] and is therefore generally formulated as a mixed non-linear optimisation problem, where some constraints are non-linear and others are not expressible in a closed form (such as transit assignment constraints). However, some recent literature reviews can be found in [10-12].

Importantly, for successful planning of a public transport system, a multimodal approach needs to be adopted, as shown by [13] and [14], in order to take into account the effect of intervention on the modal choice of users. In this framework, [15] and [16] proposed a multimodal approach for defining optimal frequencies (in terms of trains per hour or buses per hour) of public transport lines, taking into account the effects on travel demand, on other transportation systems and on external costs (such as environmental pollution and energy consumption).

Effects on user choices of the quality in public transport services were examined by [17] and [18]. Moreover, [19-22] recently investigated effects of rail service disruptions on the behaviour of passengers waiting on platforms. Finally, [23] and [24] analysed the planning of rail services by adopting different driving strategies.

In many countries, there are special laws for regulating and planning public transport services and competitive tenders for identifying the enterprises that will 
provide the mass transit services. In particular, in Italy Legislative Decree no. $422 / 1999$ [25] transfers from central government to the regions the planning and administrative tasks in the field of local public transport. Likewise, regions are obliged to enact appropriate laws and regulations, and are able to transfer to local authorities (such as provinces, provincial capitals and metropolitan cities) some tasks related to local public transport. In this context, due to the reduction in financial resources allocated to local public transport since 2011, it was necessary to replan public transport services in order to mitigate negative effects on users. Hence, in this paper, we describe the method applied in the region of Campania and summarise the proposed replanning of provincial bus services in two extreme cases.

This paper is organised as follows: Section 2 describes the main tools for planning the public transport systems; Section 3 provides two possible approaches to replanning public transport services; Section 4 summarises the application of the proposed method in two real cases; finally, conclusions and research prospects are summarised in Section 5.

\section{Public transport systems planning tools}

As shown in the literature (see for instance [26]) the planning of transportation systems, where public transport is a major component, should adopt a rational approach based on a priori simulation of effects of design interventions. In particular, it may be necessary to provide a supply model (which represents the transportation system components and their features), a travel demand model (which estimates user choices taking the transportation systems performance into account) and an interaction model (which solves the cyclic dependency between supply and demand models). The outputs of the interaction model, namely user flow and supply performance, allow evaluation of the goodness (in terms of efficiency, effectiveness and quality) of the proposed solutions.

According to the decision contexts and the planning time horizon, the following planning tools may be identified [26]:

- Strategic transportation plans;

- Feasibility studies of transportation projects;

- Tactical plans;

- Operation management programmes.

The first group of tools, indicated also as investment plans, are related to long-term (10-20 years) decisions with capital investments for the realisation of new infrastructures (e.g. metros, ports, highways) and/or the acquisition of technologies and vehicles (e.g. control systems and rolling stocks). In this case, it is necessary to simulate all transportation systems in the analysed area and provide forecast scenarios concerning the evolution of the activity system.

The feasibility studies are related to long-term decisions whose aim is to identify the technical feasibility, economic efficiency, and the priority level and execution mode of transportation projects. These studies require the formulation of alternative projects, including the do-nothing solution, defined in terms of performance and functional characteristics, and their evaluation in terms of 
functional, economic and financial points of view in the case of different transportation and activity system scenarios.

The tactical plans are short/medium term (3-6 years) tools related to decisions on projects which require limited variations in resources, generally considering the infrastructure context as invariant. In this context, it is necessary to simulate technical and functional effects of interventions jointly with the financial analysis in terms of operating costs and traffic revenues.

Finally, the last tool defines specific operational aspects of a single mode or parts of it with short-term (1-3 years) decisions. Generally, these operation management programmes aim to optimise the available resources from the standpoint of the enterprise or the transportation system operator.

In the above-described decision context, the aim of this paper consists in replanning the existing public transport system due to a reduction in available economic resources. The action can be classified as a 'tactical plan' intervention.

\section{Approaches to replanning public transport services}

The planning of public transport services is a complex problem that can be tackled in several ways and by adopting several approaches as summarised in Section 1. In this paper we consider that a public transport system already operates in the study area and that the need to replan the service in question is due only to a reduction in resources. In several European countries and/or regions in recent years there has been a reduction in available monetary resources; in Italy the available resources have decreased and some public administrations have been forced to reduce their services.

In this section, we propose two possible approaches for replanning mass-transit services under financial constraints. The first approach can be adopted when the initial services are actually able to satisfy user needs and in some time slots are probably surplus to requirements. The second approach, instead, should be used when the initial services are already inadequate or barely sufficient to serve users in the study area. In the latter case the reduction in resources arises only because of financial constraints.

Both approaches require estimation of the transportation demand and implementation of a supply model and a simulation tool able to evaluate the effects of the scenarios. Thus the proposed approaches may be viewed as methods for generating scenarios that have to be quantitatively evaluated with transportation planning models and compared with other scenarios generated with other possible approaches.

The first approach, which we identify as CLP (Change the Least Possible), seeks to change the current services as little as possible, aiming to satisfy budget constraints without modifying the network framework or routes. The main feasible interventions include some of the following:

- cutting runs with lower utility, reducing line frequency; usually, some nocturnal and off-peak runs can be cut, rescheduling services so as to save veh-kms; the same intervention can be adopted on Sunday and during public holidays; 
- shortening the path of some runs on a line, ensuring current frequencies only where demand is higher and reducing frequencies where demand is lower, so that supply matches demand more closely;

- if there is a rail/metro system, proposing feeder lines so as to maximise use of the rail/metro network; this intervention allows some lines or parts of them to be eliminated even if the users in question have to make a transfer;

- eliminating services in low-demand areas, perhaps only in off-peak hours, and replacing them with a Dial-A-Ride (DAR) system.

In order to choose where to intervene with a reduction in services, the estimated travel demand and the simulation model are adopted as a Decision Support System (DSS). The aim is to reduce the level of service where (and when) the demand is low and the impact of that reduction is minimum.

This approach tends not to modify the framework of the transit network but only the levels of service; the reduction in levels of service is accepted only during off-peak times, at night-time and during holiday periods. Thus there is no decline in service quality for commuters or students, who represent the majority of users. This approach is also well accepted by policy-makers since hardly any stakeholders suffer significant disadvantages.

The second approach, known as CFR (Change the FRamework), plans the whole network by significantly changing the service framework. In this case, since the transit services are already barely sufficient to serve the demand, it is very difficult to eliminate some runs without producing a significant reduction in levels of service.

When resources are very scarce, the new framework of the network has to maximise the level of service where and when transportation demand is higher and should be able to serve all origin-destination (OD) pairs served before the interventions. Intervention strategies may include the following:

- provision of main lines serving the OD pairs where demand is higher; the level of service of these lines should be as high as possible (high frequencies);

- provision of feeder lines towards main lines and (if any) rail/metro lines;

- provision of Dial-A-Ride (DAR) systems in low-demand areas, at least at off-peak times.

The levels of service on lines may vary greatly between peak and off-peak times. At peak hours service levels have to be as high as possible so as to cope with the trips of commuters and students; at other times, lower levels can be accepted. Also in this case, replanning requires simulation models that are able to estimate the effectiveness of the proposed service configuration.

\section{Application to two real case studies}

The proposed method was applied when replanning bus services in two of the five provinces in Campania, a region in southern Italy. Due to the economic crisis and the consequent reduction in resources for public sectors, the regional authority imposed a reduction in subsidies for public transport services and 
reformulation of the three-year service plans (which, according to the classification proposed in section 2 , have to be considered as tactical planning tools) for itself and for other local authorities. In this context, the University of Naples (Federico II) and that of Benevento (Sannio) participated in the drafting of some of those plans. In order to illustrate the application of the method to real cases, we propose a brief description of the replanning of transport services in the provinces of Naples and Avellino where we applied respectively the CLP and CFR approaches.

\subsection{The CLP approach: the case of the province of Naples (Italy)}

The province of Naples has a population of 3,079,685 inhabitants and a land area of $1,170.60 \mathrm{~km}^{2}$, with an average density of 2631 inhabitants $/ \mathrm{km}^{2}$. Travel demand on the average weekday consists of 734,562 intra-provincial trips (i.e. trips with origin and destination in the province of Naples) and 46,382 inter-provincial trips (i.e. trips with origin (or destination) in the province of Naples and with destination (or origin) in other provinces), amounting to a total of 780,944 daily trips.

The annual supply of bus services, just before the reduction, was $46,896,479$ bus-kilometres which corresponded to public subsidies of $€ 114,289,477.91$. The reduction in annual subsidies provided for a maximum number of bus-kilometres of $41,465,515$ which corresponded to $€ 101,053,899.18$ of subsidies (i.e. a reduction of $11.58 \%$ ). In the province of Naples there are 22 metro and/or regional rail lines which represent a major backbone for mobility in the area.

The replanning of the area was implemented by adopting a CLP approach. As shown in Table 1, first of all 3,556,497 bus-km (i.e. 7.58\% of initial services) of worker services were dropped due to industrial activities which were no longer active. In agreement with previous planning tools, the area was then divided by identifying three types of catchments (Figure 1), according to a trip classification, that is:

- radial catchments. Seven radial catchments were identified with high travel demand to and from the main centre of the whole area (i.e. Naples);

- local catchments. Ten local catchments were identified with travel demand to and from a main centre of the catchment, different from the province capital;

- transverse catchments. Three transverse catchments were identified with trips which, although entirely within the province of Naples, do not belong either to radial or local catchments. These trips generally have as endpoints two municipalities belonging to non-boundary local catchments.

All initial services, as well as the dropped worker services, were classified according to the three types of catchments. Moreover, it was necessary to create a fourth kind of catchments, namely interprovincial catchment, for trips with an endpoint in the province of Naples and the other endpoint in another province. For a classification of these services see Table 1. 


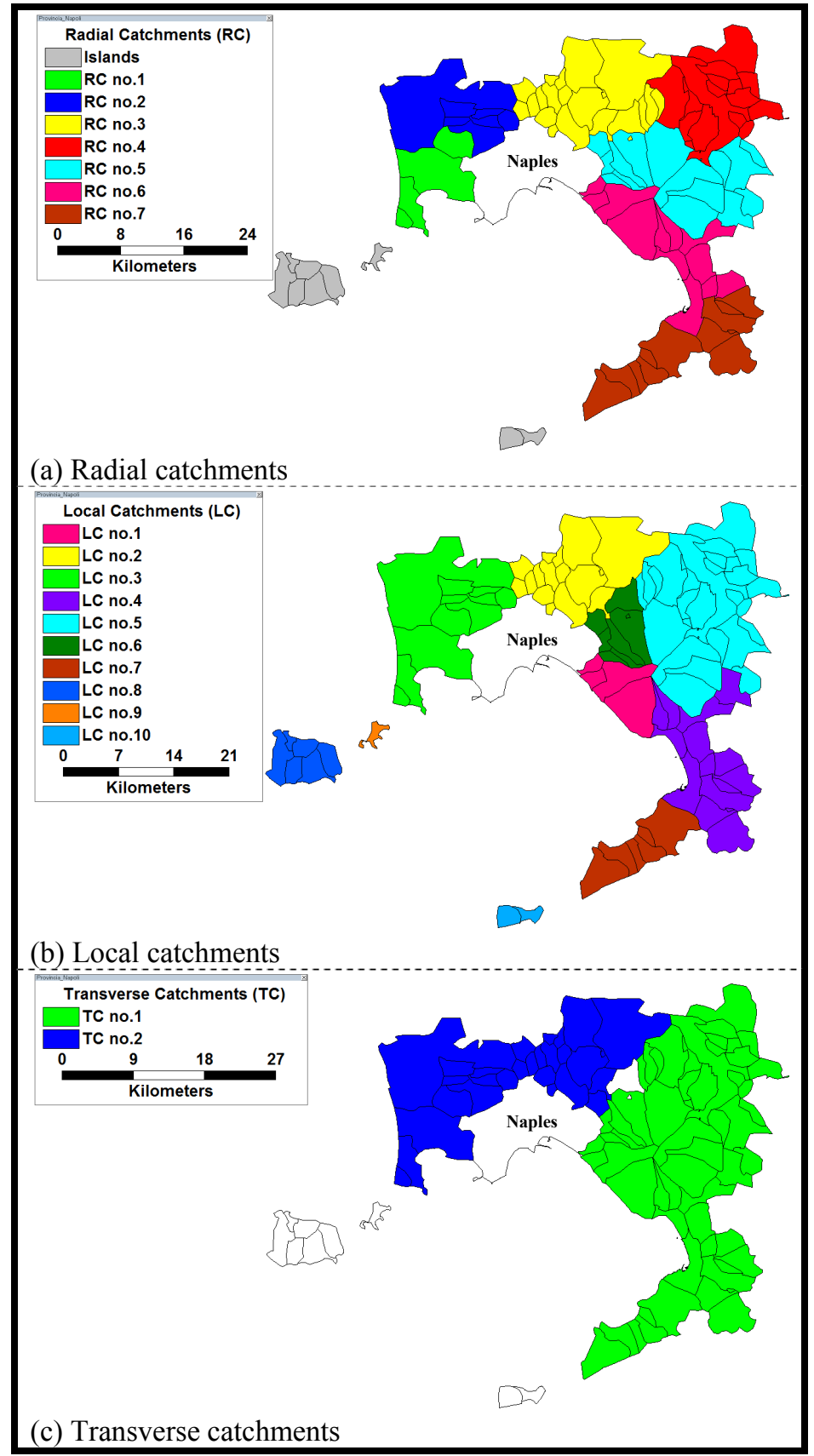

Figure 1: $\quad$ Radial (a), local (b) and transverse (c) catchments in the province of Naples (Italy). 
A previous planning tool of the province of Naples had identified, in the case of an increase in available resources, some partition coefficients to balance the transport supply among the different areas. Hence, by applying the above coefficients and using a uniform rate of reduction, we identified the target value of bus supply for each catchment.

It is worth noting that some services, amounting to $2,564,758$ bus-km, were to be considered as invariant since their contracts were to expire at a date later than the application of the new plan.

Table 1: Target supply definition in the case of the province of Naples (Italy).

\begin{tabular}{lrrrr}
\hline Catchment & Initial supply & $\begin{array}{c}\text { Dropped } \\
\text { worker } \\
\text { services }\end{array}$ & $\begin{array}{c}\text { Real } \\
\text { initial supply }\end{array}$ & Target supply \\
\hline Radial & $19,717,869$ & 769,097 & $18,948,772$ & $18,249,488$ \\
Local & $17,640,626$ & 372,216 & $17,268,410$ & $16,654,658$ \\
Transverse & $3,284,825$ & $2,207,959$ & $1,076,866$ & 921,583 \\
Interprovincial & $6,253,159$ & 207,225 & $6,045,934$ & $5,639,786$ \\
\hline Total & $\mathbf{4 6 , 8 9 6 , 4 7 9}$ & $\mathbf{3 , 5 5 6 , 4 9 7}$ & $\mathbf{4 3 , 3 3 9 , 9 8 2}$ & $\mathbf{4 1 , 4 6 5 , 5 1 5}$ \\
\hline
\end{tabular}

Based on the above premises, the bus services were replanned line by line by adopting the following criteria:

- in all catchments, some night-time and holiday services were reduced;

- services in the radial catchments were reduced as follows:

- at peak hours runs were left intact since residual rail capacity (in the direction to Naples) did not allow any kind of interchange;

- at off-peak hours, half of the runs were stopped at the nearest railway station, allowing continuation of the trip through modal interchange;

- services in the local catchments were left as unchanged as possible, replacing in some cases, especially at off-peak hours, some runs with Dial-A-Ride (DAR) services;

- services in the transverse and interprovincial catchments were left unchanged as possible.

Finally, some resources were identified, namely reserve services, associated to radial and local catchments but not identified in terms of lines and/or runs, in order to solve particular contingencies. Results of the replanning process in the province of Naples are summarised in Table 2.

Table 2: Future services definition in the case of the province of Naples (Italy).

\begin{tabular}{lccccc}
\hline Catchment & $\begin{array}{c}\text { Proposed } \\
\text { traditional } \\
\text { services }\end{array}$ & $\begin{array}{c}\text { Proposed } \\
\text { DAR } \\
\text { services }\end{array}$ & $\begin{array}{c}\text { Invariant } \\
\text { services }\end{array}$ & $\begin{array}{c}\text { Reserve } \\
\text { services }\end{array}$ & $\begin{array}{c}\text { Future } \\
\text { services }\end{array}$ \\
\hline Radial & $16,669,060$ & - & 42,513 & 657,565 & $17,369,138$ \\
Local & $13,963,021$ & 750,000 & $2,287,801$ & 350,000 & $17,350,822$ \\
Transverse & 781,947 & - & 234,444 & - & $1,016,391$ \\
Interprovincial & $5,729,164$ & - & - & - & $5,729,164$ \\
\hline Total & $\mathbf{3 7 , 1 4 3 , 1 9 2}$ & $\mathbf{7 5 0 , 0 0 0}$ & $\mathbf{2 , 5 6 4 , 7 5 8}$ & $\mathbf{1 , 0 0 7 , 5 6 5}$ & $\mathbf{4 1 , 4 6 5 , 5 1 5}$ \\
\hline
\end{tabular}




\subsection{The CFR approach: the case of the province of Avellino (Italy)}

The province of Avellino has a population of 439,036 and a land area of $2,791.64 \mathrm{~km}^{2}$, with an average density of 157 inhabitants $/ \mathrm{km}^{2}$. Travel demand, on the average weekday, comprises 80,840 intra-provincial trips (i.e. trips with origin and destination in the province) and 12,144 inter-provincial trips (i.e. trips with origin [or destination] in the province of Avellino and with destination [or origin] in other provinces), amounting to a total of 92,984 daily trips.

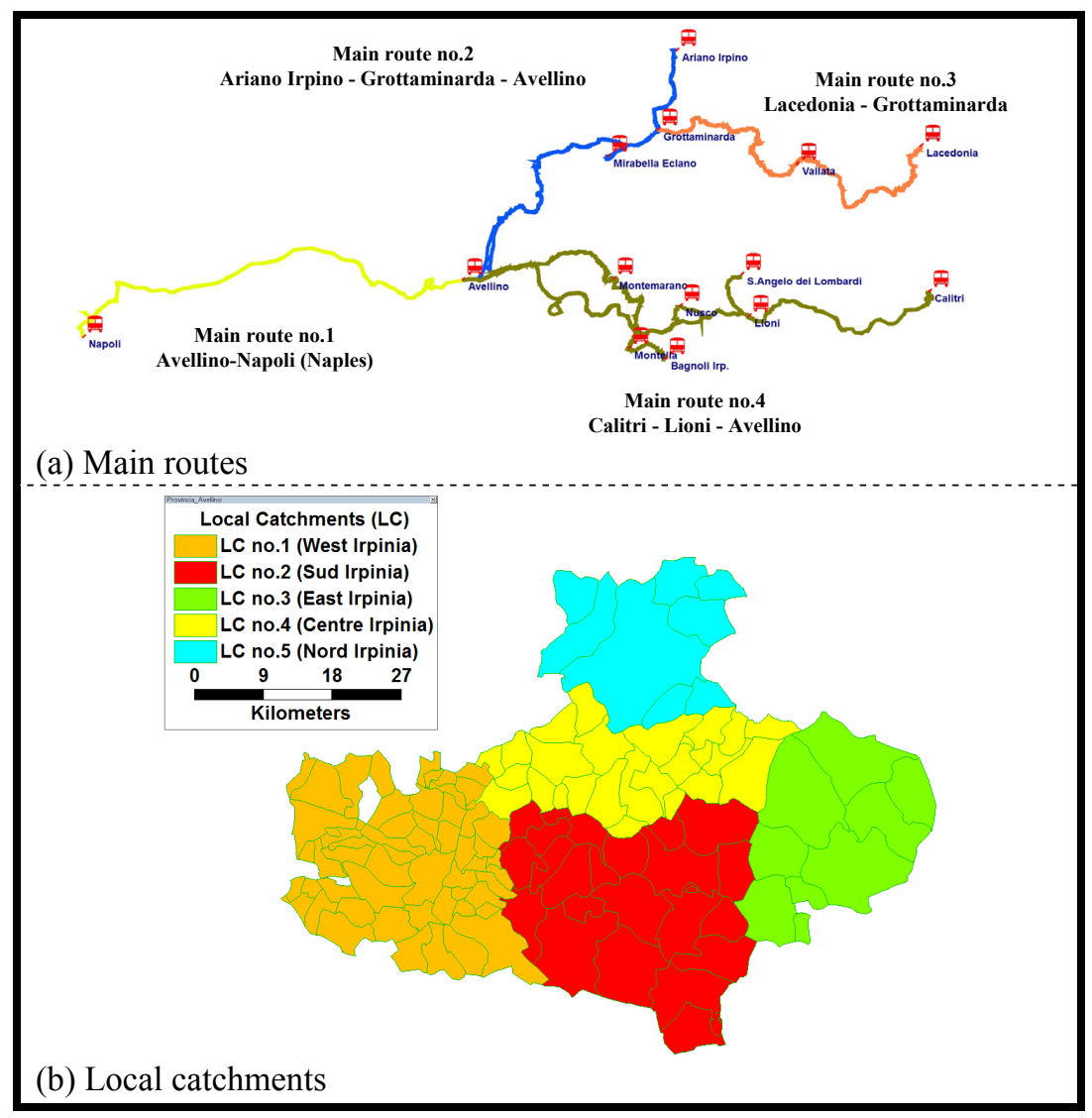

Figure 2: Main routes (a) and local catchments (b) in the province of Avellino (Italy).

The annual supply of bus services, just before the reduction, was 15,012,988 bus-kilometres which corresponded to $€ 25,322,800.72$ of public subsidies. The reduction in annual subsidies provided for a maximum of 12,194,609 bus-kilometres, corresponding to $€ 20,568,966.92$ of subsidies (i.e. a reduction of $18.77 \%)$. 
In the province of Avellino there are three regional rail lines, whose location and services (in terms of frequencies) do not allow their use as a backbone for mobility in the area.

Replanning of the area was implemented by adopting a CFR approach. As in the case of the province of Naples, a detailed comparison of catchments in terms of services and resources before and after the replanning proposal cannot be made. Four kinds of services were identified in relation to the main characteristics of travel demand:

- main routes. Four main routes where a large number of trips occurred;

- local catchments. In agreement with previous planning tools, the area was divided into five local catchments with considerable travel demand to and from a main centre of the catchment;

- transverse catchment. One transverse catchment (coinciding with the entire province of Avellino) was identified, characterised by trips which, although entirely within the province of Avellino, do not belong either to a main route or local catchments;

- interprovincial catchments. Some catchments related to trips with an endpoint in the province of Avellino and the other endpoint in another province were identified.

Details of the main routes and local catchments are shown in Figure 2.

Based on the above premises, the bus services were replanned line by line by adopting an ex-novo approach. In particular, there were identified some resources, devoted to school and worker services, associated to the whole province in order to satisfy particular contingencies which was not possible to define in this phase of the planning process.

Our findings for the replanning process in the province of Avellino are summarised in Table 3.

Table 3: Definition of future services in the case of the province of Avellino (Italy).

\begin{tabular}{lcccc}
\hline \multicolumn{1}{c}{ Context } & $\begin{array}{c}\text { Proposed } \\
\text { traditional } \\
\text { services }\end{array}$ & $\begin{array}{c}\text { Proposed } \\
\text { DAR } \\
\text { services }\end{array}$ & $\begin{array}{c}\text { Proposed } \\
\text { urban } \\
\text { services }\end{array}$ & $\begin{array}{c}\text { Proposed } \\
\text { services } \\
\text { (total) }\end{array}$ \\
\hline Main routes & $3,724,230$ & 200,000 & - & $3,924,230$ \\
Local catchments & $2,554,019$ & 780,000 & 270,000 & $3,604,019$ \\
Transverse catchment & 384,445 & - & - & 384,445 \\
Interprovincial catchments & $3,281,915$ & - & - & $3,281,915$ \\
School and worker services & $1,000,000$ & & & $1,000,000$ \\
\hline Total & $\mathbf{1 0 , 9 4 4 , 6 0 9}$ & $\mathbf{9 8 0 , 0 0 0}$ & $\mathbf{2 7 0 , 0 0 0}$ & $\mathbf{1 2 , 1 9 4 , 6 0 9}$ \\
\hline
\end{tabular}

\section{Conclusions and research prospects}

In the literature, methods for planning public transport services have been widely described [26]. However, there are no consolidated methods for operating in the case of reductions in available resources. Therefore, in this paper, we propose two approaches to be applied in extreme cases, namely 'Change the Least 
Possible' and 'Change the FRamework', applicable respectively when initial services are actually able to satisfy user needs and when initial services are already inadequate or barely sufficient to serve users. Feasibility of the proposed methods, their interference with pre-existing planning tools and other difficulties (such as the presence of contracts which cannot be modified) are described and shown in the application to two real cases.

Future research will consider the application of the proposed approaches to other contexts both in terms of area (i.e. other Italian regions and/or other European or non-European countries) and/or service type (such as rail services). Finally, regional contexts might be identified in which to apply a hybrid approach whereby features of the two methods are merged.

\section{References}

[1] Gori, S., Nigro, M. \& Petrelli, M., The impact of land use characteristics for sustainable mobility: The case study of Rome. European Transport Research Review, 4(3), pp. 153-166, 2012.

[2] Gallo, M., A fuel surcharge policy for reducing road traffic greenhouse gas emissions. Transport Policy, 18(2), pp. 413-424, 2011.

[3] Gallo, M., D’Acierno, L. \& Montella, B., A multilayer model to simulate cruising for parking in urban areas. Transport Policy, 18(5), pp. 735-744, 2011.

[4] D’Acierno, L., Ciccarelli, R., Montella, B. \& Gallo, M., A multimodal multiuser approach for analysing pricing policies in urban contexts. Journal of Applied Sciences, 11(4), pp. 599-609, 2011.

[5] Biggiero, L., The impact of transport management on local activities system: The role of limited traffic zones. WIT Transactions on the Built Environment, 138, 2014.

[6] Ceder, A. \& Wilson, N.H.M., Bus network design. Transportation Research Part B, 20(4), pp. 331-344, 1986.

[7] Newell, G., Some issue relating to the optimal design of bus lines. Transportation Science, 13(1), pp. 20-35, 1979.

[8] Magnanti, T.L. \& Wong, R.T., Network design and transportation planning: models and algorithms. Transportation Science, 18(1), pp. 1-55, 1984.

[9] Baaj, M.H. \& Mahmassani, H.S., An AI-based approach for transit route system planning and design. Journal of Advanced Transportation, 25(2), pp. 187-210, 1991.

[10] Desaulniers, G. \& Hickman, M., Public transit. Transportation, eds. C. Barnhart \& G. Laporte, North-Holland: Amsterdam, The Netherlands, pp. 69-120, 2007.

[11] Guihaire, V. \& Hao, J.-K., Transit network design and scheduling: A global review. Transportation Research Part A, 42(10), pp. 1251-1273, 2008.

[12] Kepaptsoglou, K. \& Karlaftis, M., Transit route network design problem: review. Journal of Transportation Engineering, 135(8), pp. 491-505, 2009. 
[13] Montella, B., Gallo, M. \& D’Acierno, L., Multimodal network design problems. Advances in Transport, 5, pp. 405-414, 2000.

[14] Cipriani, E., Gori, S. \& Petrelli, M., A bus network design procedure with elastic demand for large urban areas. Public Transport, 4(1), pp. 57-76, 2012.

[15] Gallo, M., Montella, B. \& D'Acierno, L., The transit network design problem with elastic demand and internalisation of external costs: An application to rail frequency optimisation. Transportation Research Part C, 19(6), pp. 1276-1305, 2011.

[16] Gallo, M., D’Acierno, L. \& Montella, B., A multimodal approach to bus frequency design. WIT Transactions on the Built Environment, 116, pp. 193-204, 2011.

[17] Pagliara, F., Delaplace, M. \& Vassallo, J.M., High-speed train and tourists: what is the link? Evidence from the French and the Spanish capitals. WIT Transactions on the Built Environment, 138, 2014.

[18] Cascetta, E. \& Cartenì, A., The hedonic value of railways terminals. A quantitative analysis of the impact of stations quality on traveller's behaviour. Transportation Research Part A, 61, pp. 41-52, 2014.

[19] Quaglietta, E., D’Acierno, L., Punzo, V., Nardone, R. \& Mazzocca, N., A simulation framework for supporting design and real-time decisional phases in railway systems. Proc. of the 14th IEEE Conference on Intelligent Transportation Systems (ITSC), art. no. 6082913, pp. 846-851, 2011.

[20] D'Acierno, L., Gallo, M., Montella, B. \& Placido, A., Analysis of the interaction between travel demand and rail capacity constraints. WIT Transactions on the Built Environment, 128, pp. 197-207, 2012.

[21] D'Acierno, L., Gallo, M., Montella, B. \& Placido, A., The definition of a model framework for managing rail systems in the case of breakdowns. Proc. of the 16th IEEE Conference on Intelligent Transportation Systems (ITSC), pp. 1059-1064, 2013.

[22] Ercolani, M., Placido, A., D’Acierno, L. and Montella, B., The use of microsimulation models for the planning and management of metro systems. WIT Transactions on the Built Environment, 135, 2014.

[23] Corapi, G., Sanzari, D., De Martinis, V., D’Acierno, L. \& Montella, B., A simulation-based approach for evaluating train operating costs under different signalling systems. WIT Transactions on the Built Environment, 130, pp. 149-161, 2013.

[24] De Martinis, V., Gallo, M. \& D’Acierno, L., Estimating the benefits of energy-efficient train driving strategies: a model calibration with real data. WIT Transactions on the Built Environment, 130, pp. 201-211, 2013.

[25] Decreto Legislativo n. 422/1999, Conferimento alle regioni ed agli enti locali di funzioni e compiti in materia di trasporto pubblico locale, a norma dell'articolo 4, comma 4, della legge 15 marzo 1997, n. 59.

[26] Cascetta, E., Transportation systems analysis: models and applications. Springer: New York (NY), USA, 2009. 